\title{
Structural and dielectric properties of $\mathrm{Ba}_{0.95} \mathrm{Bi}_{0.05} \mathbf{T i}_{1-}$ ${ }_{x} \mathrm{Fe}_{\mathrm{x}} \mathrm{O}_{3}$ ceramics at $\mathrm{x}=0.0,0.1$ and 0.2 prepared by solid state method
}

\author{
Najwa Gouitaa ${ }^{1, *}$, Taj-dine ${ }^{1,}$ Lamcharfi, Lamfadal Bouayad ${ }^{1}$, Farid AbdI ${ }^{1}$ and \\ Mohammed Naciri Bennani ${ }^{2}$ \\ ${ }^{1}$ Electrical Engineering Department. Signals, Systems and Components Laboratory (LSSC). Fez, Morocco. \\ ${ }^{2}$ Chemistry-biology applied to the environment laboratory Materials and applied catalysis team. Meknes, \\ Morocco
}

\begin{abstract}
The $\mathrm{Ba}_{0.95} \mathrm{Bi}_{0.05} \mathrm{Ti}_{1-\mathrm{x}} \mathrm{Fe}_{\mathrm{x}} \mathrm{O}_{3}$ ceramics at $(\mathrm{x}=0.0,0.1$ and 0.2$)$ were prepared by the solid-state reaction method. The effect of iron substitution on structural and dielectric properties of $\mathrm{Ba}_{0.95} \mathrm{Bi}_{0.05} \mathrm{TiO}_{3}$ ceramic was studied. These compounds are found to crystallize in only tetragonal phase for $\mathrm{x}=0.0$ and 0.1 and the mixture of tetragonal and hexagonal phases for $\mathrm{x}=0.2$. The dielectric properties of $\mathrm{Ba}_{0.95} \mathrm{Bi}_{0.05} \mathrm{Ti}_{1-\mathrm{x}} \mathrm{Fe}_{\mathrm{x}} \mathrm{O}_{3}$ ceramics at $\mathrm{x}=0.0,0.1$ and 0.2 of $\mathrm{Fe}$-doping concentration. The dielectric measurements as a function of temperature and frequency are studied and showed two diffuse phase transition and relaxation phenomena. The evolution of dielectric permittivity as a function of the frequency of undoped $\mathrm{Ba}_{0.95} \mathrm{Bi}_{0.05} \mathrm{TiO}_{3}$ show a relaxation phenomenon for which is displaced to the higher frequencies accompanied by a decrease in dielectric constant when $\mathrm{x}$ increase. The Complex impedance Cole-Cole plots showed a negative temperature coefficient of resistivity (NTCR) behavior of the $\mathrm{Ba}_{0.95} \mathrm{Bi}_{0.05} \mathrm{Ti}_{1-\mathrm{x}} \mathrm{Fe}_{\mathrm{x}} \mathrm{O}_{3}$ materials and increased in grain and grain boundaries resistivity. The relaxation behavior in the test materials is found to be of non-Debye type.
\end{abstract}

Keywords: $\mathrm{Ba}_{0.95} \mathrm{Bi}_{0.05} \mathrm{Ti}_{1-\mathrm{x}} \mathrm{Fe}_{\mathrm{x}} \mathrm{O}_{3}$ ceramics Solid state, structural, dielectric properties, phase transition, Complex impedance.

\section{Introduction}

During the recent decade, multiferroic materials have attracted the great attention of researchers over the last decade because of interest in their potential at information storage, MERAM, spintronics etc ${ }^{1,2}$.

The tetragonal perovskite $\mathrm{BaTiO}_{3}$ with a Curie temperature $(\mathrm{Tc})$ of $120{ }^{\circ} \mathrm{C}$, has been adapted as a popular candidate in the research of multiferroic materials is the most ferroelectric material which exhibits a high dielectric constant, low dielectric loss and good piezoelectric, pyroelectric and ferroelectric properties ${ }^{3}$. To achieve a magnetic ordering in the semiconducting $\mathrm{BaTiO}_{3}$, the magnetic ions can be doping into it for extending the field of its application ${ }^{4}$. The Fe doped $\mathrm{BaTiO} 3$ has been reported to have magnetic ordering, where the $\mathrm{Fe}$ ions substitute into the $\mathrm{Ti}^{4+}$ sites ${ }^{5,6}$. However, the major problems of earlier BTFO ceramic are the high Curie temperature which is displaced to the higher temperature with increasing of Fe doping contents and the low dielectric constant which limited their application. As an effective approach in altering or improving physical

*Corresponding author: Najwa Gouitaa

E-mail adresse: najwa.gouitaa@gmail.com

DOI: http://dx.doi.org/10.13171/mjc8319050305ng properties, co-doping into $\mathrm{ABO}_{3}$ compounds at Asite and $\mathrm{B}$-site is widely used. It has been reported that the substitution of $\mathrm{Bi}^{3+}$ ions into the $\mathrm{Ba}^{2+}$ sites $\left(\mathrm{Ba}_{1-\mathrm{x}} \mathrm{Bi}_{\mathrm{x}} \mathrm{TiO} 3\right)$ achieves a maximum dielectric constant at $\mathrm{x}=0.05^{8}$. The structure of $\mathrm{Ba}_{1-\mathrm{x}} \mathrm{Bi}_{\mathrm{x}} \mathrm{TiO} 3$ $(x \leq 0.1)$ was reported to be of a tetragonal phase ${ }^{9,10}$.

The present study is intended to study the influence of $\mathrm{Fe}$ doping on structural and dielectric properties of $\mathrm{Ba}_{0.95} \mathrm{Bi}_{0.05} \mathrm{Ti}_{1-\mathrm{x}} \mathrm{Fe}_{\mathrm{x}} \mathrm{O}_{3}$ solid solution at $\mathrm{X}=0.0,0.1$ and $0.2 \mathrm{Fe}$-doping concentration.

\section{Experimental}

The $\mathrm{Ba}_{0.95} \mathrm{Bi}_{0.05} \mathrm{Ti}_{1-\mathrm{x}} \mathrm{Fe}_{\mathrm{x}} \mathrm{O}_{3}$ ceramics at $(\mathrm{x}=0.0,0.1$ and 0.2 ) were prepared by the conventional solidstate method. The $\mathrm{BaCO}_{3}, \mathrm{Bi}_{2} \mathrm{O}_{3}, \mathrm{TiO}_{2}$ and $\mathrm{Fe}_{2} \mathrm{O}_{3}$ compounds were weighted in stoichiometric proportion and milled under acetone for $4 \mathrm{~h}$. After that, the powders were dried at $70^{\circ} \mathrm{C}$ for $48 \mathrm{~h}$. The dried powders were mixed using agate mortar and pestle for $30 \mathrm{~min}$ and then placed in an alumina nacelle for calcination in air at $1100{ }^{\circ} \mathrm{C}$ for $4 \mathrm{~h}$. The crystal structure of the product $\left(\mathrm{Ba}_{0.95} \mathrm{Bi}_{0.05} \mathrm{Ti}_{1-\mathrm{x}} \mathrm{Fe}_{\mathrm{x}} \mathrm{O}_{3}\right)$ was

Received February 11, 2019 Accepted March 23, 2019

Published May 3, 2019 
characterized by X-ray diffraction (XPERT-PRO with

$\mathrm{Cu} \mathrm{K} \alpha$ radiation with $\lambda=1.5406 \mathrm{~A}^{\circ}$ ). The calcined powders were pressed into pellets and sintered in air at $1200{ }^{\circ} \mathrm{C}$ for $6 \mathrm{~h}$. The dielectric properties as a function of frequency and temperature were tested with Agilent E4980A (20Hz-2MHz).

\section{Results and discussion}

\section{X-ray diffraction results}

The Fig.1a shows the XRD patterns of $\mathrm{Ba}_{0.95} \mathrm{Bi}_{0.05} \mathrm{Ti}_{1-\mathrm{x}} \mathrm{Fe}_{\mathrm{x}} \mathrm{O}_{3}$ ceramics for $\mathrm{x}=0.0,0.1$ and 0.2 . calcined at $1100^{\circ} \mathrm{C} / 4 \mathrm{~h}$. The synthesized samples show a pure perovskite structure with no secondary phases detected. For $\mathrm{x}=0.0$ and 0.1 only a tetragonal phase was observed ${ }^{11}$. While the X-ray analysis of Fe doping $\mathrm{Ba}_{0.95} \mathrm{Bi}_{0.05} \mathrm{TiO}_{3}$ at $\mathrm{x}=0.2$ showed the coexistence of tetragonal and hexagonal phase. The tetragonal (101) peak and hexagonal (104) peak were zoomed in Fig.1b. The X-ray analysis of these peaks reveals that the (104) hexagonal peak appears at $\mathrm{x}=0.2$ while the intensity of (101) tetragonal peak decreases with the increase of $\mathrm{Fe}$ content. So the $\mathrm{Fe}$ additive stabilizes the hexagonal phase in $\mathrm{Ba}_{0.95} \mathrm{Bi}_{0.05} \mathrm{TiO}_{3}$ ceramic and removes the tetragonal phase formation. The (101) peak shifted to higher angles for all samples which can be attributed to the presence of $\mathrm{Fe}^{4+}$ with the ionic radius $\left[\mathrm{r}_{\mathrm{i}}\left(\mathrm{Fe}^{4+}\right)=\right.$ $0.585 \AA$ ] smaller than the ionic radius of $\mathrm{Ti}_{4+}$ $\left(\operatorname{ri}\left(\mathrm{Ti}^{4+}\right)=0.605 \AA\right)^{12}$

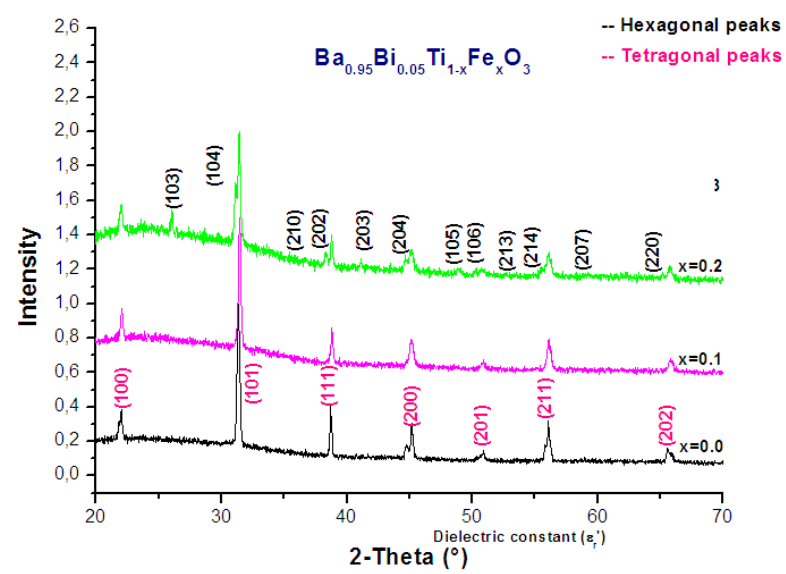

Figure 1a. XRD patterns of $\mathrm{Ba}_{0.95} \mathrm{Bi}_{0.05} \mathrm{Ti}_{1-\mathrm{x}} \mathrm{Fe}_{\mathrm{x}} \mathrm{O}_{3}$ ceramics for $\mathrm{x}=0.0,0.1$ and 0.2

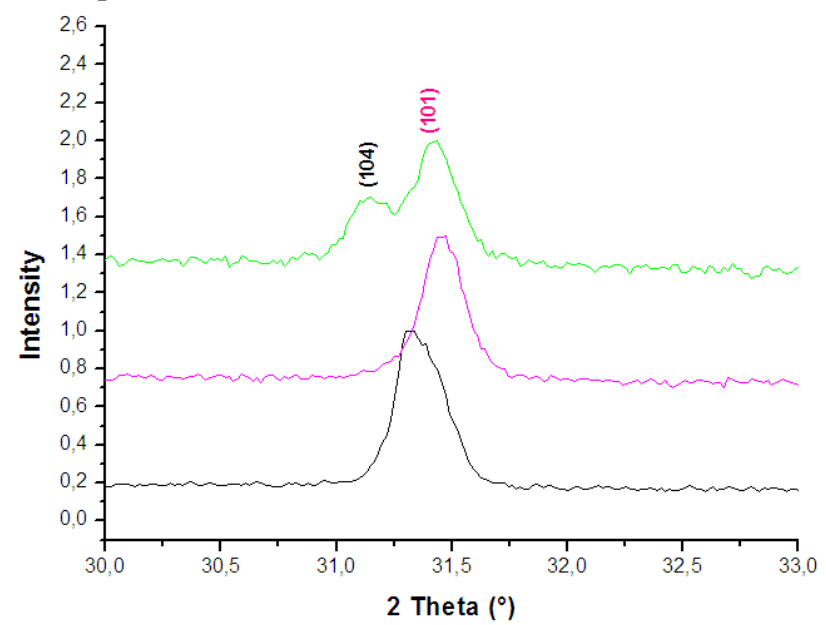

Figure 1b. XRD peaks (101) for the tetragonal phase and (104) for the hexagonal phase of $\mathrm{Ba}_{0.95} \mathrm{Bi}_{0.05} \mathrm{Ti}_{1-}$ ${ }_{x} \mathrm{Fe}_{\mathrm{x}} \mathrm{O}_{3}$ ceramics for $\mathrm{x}=0.0,0.1$ and 0.2 .

\section{Rietveld refinement}

To obtain more detailed information about the crystallographic structure of $\mathrm{Ba}_{0.95} \mathrm{Bi}_{0.05} \mathrm{Ti}_{1-\mathrm{x}} \mathrm{Fe}_{\mathrm{x}} \mathrm{O}_{3}$ solids for $\mathrm{x}=0.0,0.1$ and 0.2 , we performed full pattern matching the refinement of the XRD spectra using the Full prof program package as shown in Fig. 2. A Pseudo-Voigt function described the peak shapes. From the results of the refinement (Fig. 2 and Table.1), only one phase is detected for $\mathrm{x}=0.0$ and $\mathrm{x}=0.1$ with $\mathrm{P} 4 \mathrm{~m} \mathrm{~m}$ space group while two phases are found at $\mathrm{x}=0.2$ prepared sample with $\mathrm{P} 6_{3} \mathrm{Im} \mathrm{m} \mathrm{c}$ space group. There is no other observable impurity phase in the system. According to the refinements, most of the $\mathrm{Fe}$ ions are believed to be embedded in $\mathrm{Ba}_{0.95} \mathrm{Bi}_{0.05} \mathrm{TiO}_{3}$ crystal lattice and substitute for $\mathrm{Ti}$ ions, so there is no obvious secondary phase observed in diffraction patterns. A good agreement between the observed and calculated patterns was 
obtained with $\mathrm{R}_{\mathrm{p}} \leq 8.59 \%, \mathrm{R}_{\mathrm{wp}} \leq 13.4 \%$ and chi-

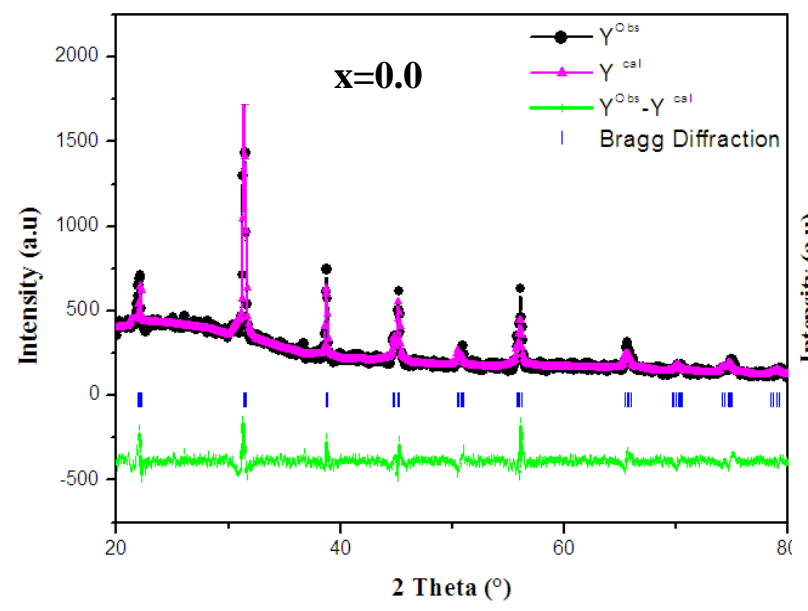

squared $\left(\chi^{2}\right) \leq 3.85$ for all ceramics.

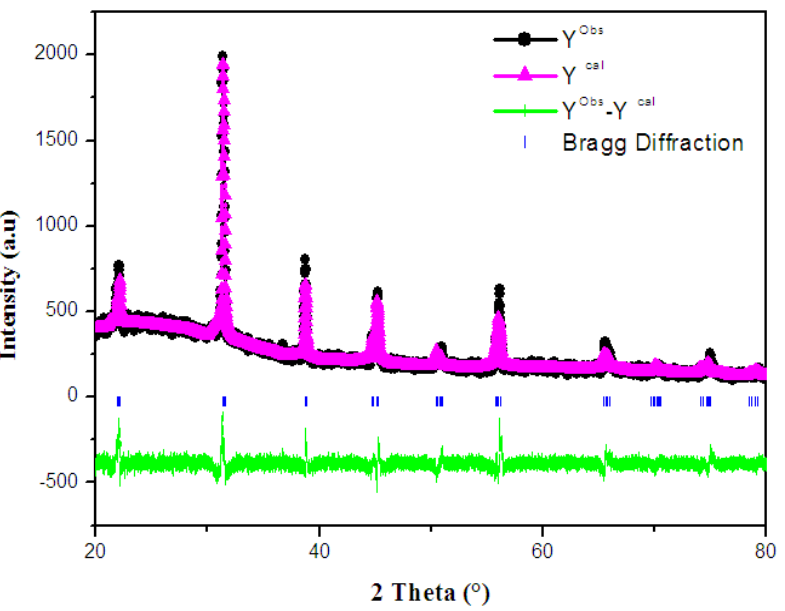

$\mathrm{x}=0.1$

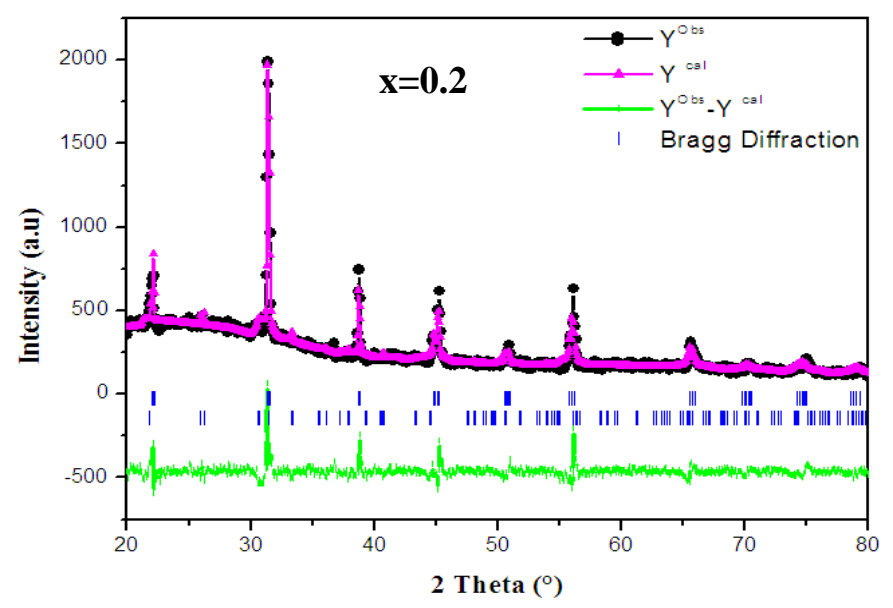

Figure 2. Rietveld rafinement of $\mathrm{Ba}_{0.95} \mathrm{Bi}_{0.05} \mathrm{Ti}_{1-\mathrm{x}} \mathrm{Fe}_{\mathrm{x}} \mathrm{O}_{3}$ ceramics for $\mathrm{x}=0.0,0.1$ and 0.2.

Table 1. Refined structural parameters of $\mathrm{Ba}_{0.95} \mathrm{Bi}_{0.05} \mathrm{Ti}_{1-\mathrm{x}} \mathrm{Fe}_{\mathrm{x}} \mathrm{O}_{3}$ ceramics for $\mathrm{x}=0.0,0.1$ and $0.2 \mathrm{x}$.

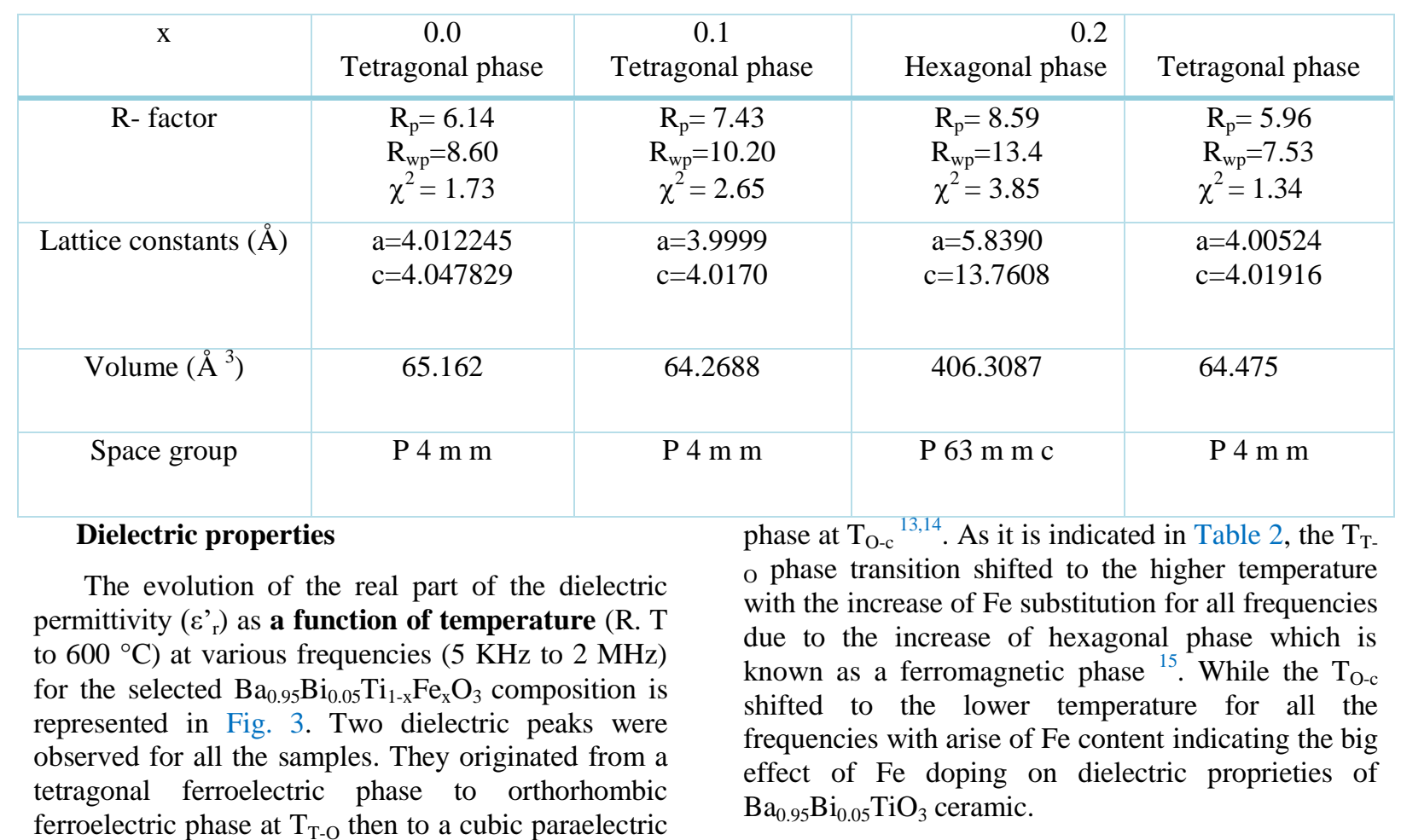




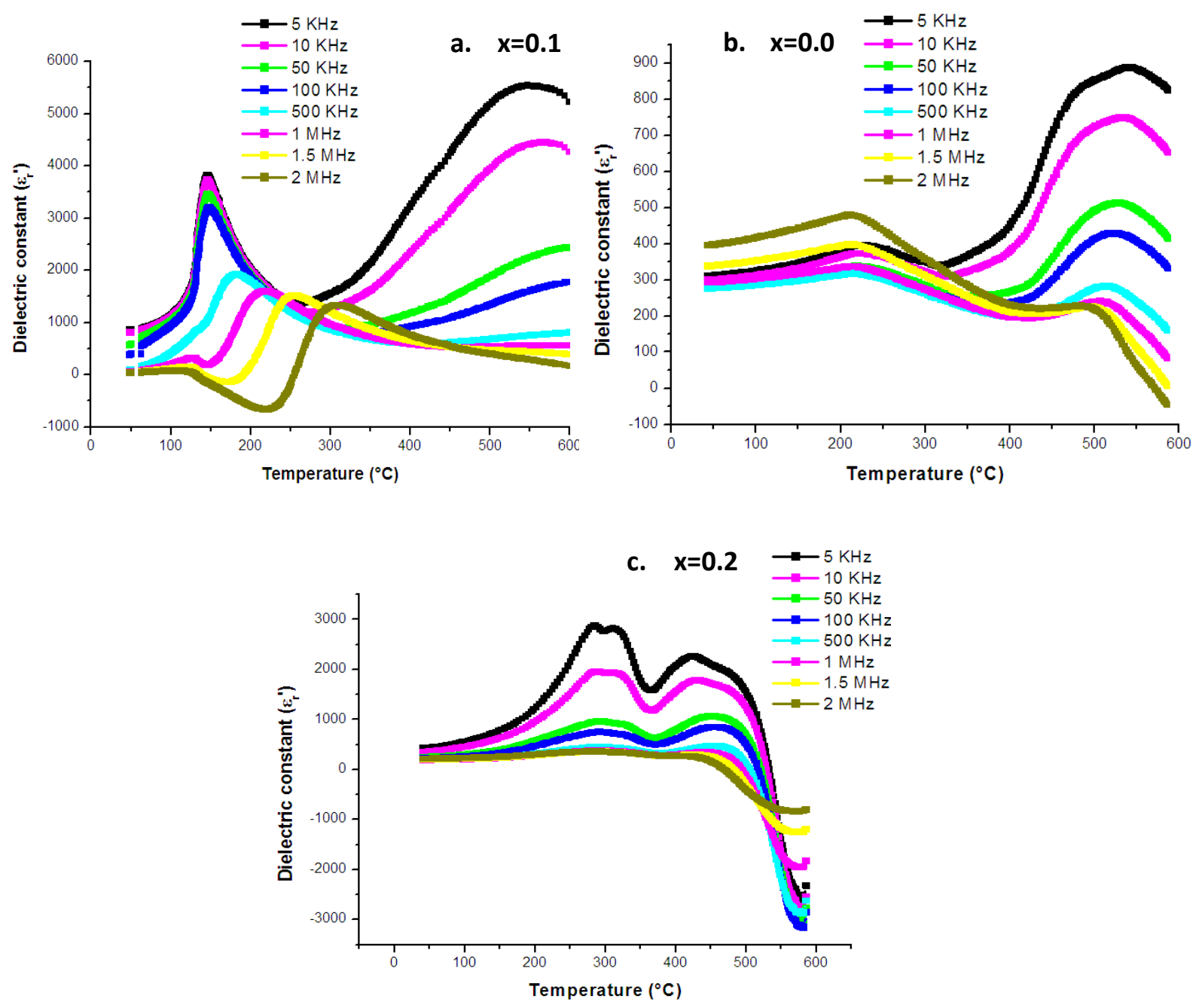

Figure 3. Dielectric constant dependent temperature at different frequencies of $\mathrm{Ba}_{0.95} \mathrm{Bi}_{0.05} \mathrm{Ti}_{1-\mathrm{x}} \mathrm{Fe}_{\mathrm{x}} \mathrm{O}_{3}$ ceramics for $\mathrm{x}=\mathrm{a} .0 .0$, b. 0.1 and c. 0.2 .

Table 2. $\mathrm{T}_{\mathrm{m}}, \mathrm{T}_{\mathrm{T}-\mathrm{O}}, \mathrm{T}_{\mathrm{O}-\mathrm{c}}, \varepsilon_{1, \max }$ and $\varepsilon_{2, \max }$ values at different frequencies of $\mathrm{Ba}_{0.95} \mathrm{Bi}_{0.05} \mathrm{Ti}_{1-\mathrm{x}} \mathrm{Fe}_{\mathrm{x}} \mathrm{O}_{3}$ ceramics.

\begin{tabular}{|c|c|c|c|c|c|c|}
\hline & $\begin{array}{c}\text { Fréquency } \\
(\mathrm{KHz})\end{array}$ & $\mathrm{T}_{\mathrm{m}}\left({ }^{\circ} \mathrm{C}\right)$ & $\mathrm{T}_{\mathrm{c}}\left({ }^{\circ} \mathrm{C}\right)$ & $\mathrm{T}_{\mathrm{T}-\mathrm{O}}\left({ }^{\circ} \mathrm{C}\right)$ & $\varepsilon_{1, \max }$ & $\varepsilon_{2, \text { max }}$ \\
\hline \multirow{6}{*}{0.0} & 5 & --- & 145 & 535 & 3846 & 5540 \\
\hline & 50 & --- & 145 & 594 & 3505 & 2427 \\
\hline & 100 & --- & 145 & $>600$ & 3247 & 1828 \\
\hline & 500 & 175 & & $>600$ & 1947 & --- \\
\hline & 1000 & 212 & & $>600$ & 1606 & --- \\
\hline & 2000 & 302 & & $>600$ & 1350 & --- \\
\hline \multirow{6}{*}{0.1} & 5 & 235 & & 540 & 401 & 890 \\
\hline & 50 & 232 & & 530 & 342 & 516 \\
\hline & 100 & 225 & & 516 & 342 & 433 \\
\hline & 500 & 227 & & 511 & 323 & 288 \\
\hline & 1000 & 226 & & 508 & 390 & 250 \\
\hline & 2000 & 215 & & 491 & 482 & 234 \\
\hline \multirow{6}{*}{0.2} & 5 & 283 & & 245 & 2326 & 2903 \\
\hline & 50 & 285 & & 427 & 1755 & 953 \\
\hline & 100 & 287 & & 449 & 846 & 715 \\
\hline & 500 & 289 & & 457 & 511 & 481 \\
\hline & 1000 & 289 & & 451 & 344 & 413 \\
\hline & 2000 & 386 & & 445 & 178 & 403 \\
\hline
\end{tabular}


The phases transition in our sample presents a relaxor-like behavior due to the relaxation process associated with defect dipoles such as the oxygenvacancy and the valence fluctuation of $\mathrm{Fe}$ ions (between $\mathrm{Fe}^{3+}$ and $\mathrm{Fe}^{2+}$ ) ${ }^{16}$. Literature reports that the deviation from oxygen stoichiometry leads to valence fluctuation of $\mathrm{Fe}$ ions from $\mathrm{Fe}^{3+}$ to $\mathrm{Fe}^{2+}$ state in $\mathrm{BaTiO}_{3}$, resulting in a high conductivity ${ }^{17,18}$. In this case, the short-range hopping of oxygen vacancy and valence variation of iron ions, similar to the reorientation of the dipole, lead to a dielectric anomaly reflected in the increase of the two dielectric permittivity values $\left(\varepsilon_{1, \max }\right.$, and $\left.\varepsilon_{2, \max }\right)$ at $\mathrm{x}=0.1$ and then the decrease of these values at $x=0.2$ for all the frequencies (Table.2). Generally, in perovskite ferroelectric compounds, oxygen vacancies are considered as one of the mobile charge carriers, and mostly in titanates, the ionization of oxygen vacancies creates conduction electrons, a process which is defined by Krôger Vink notation ${ }^{19}$.
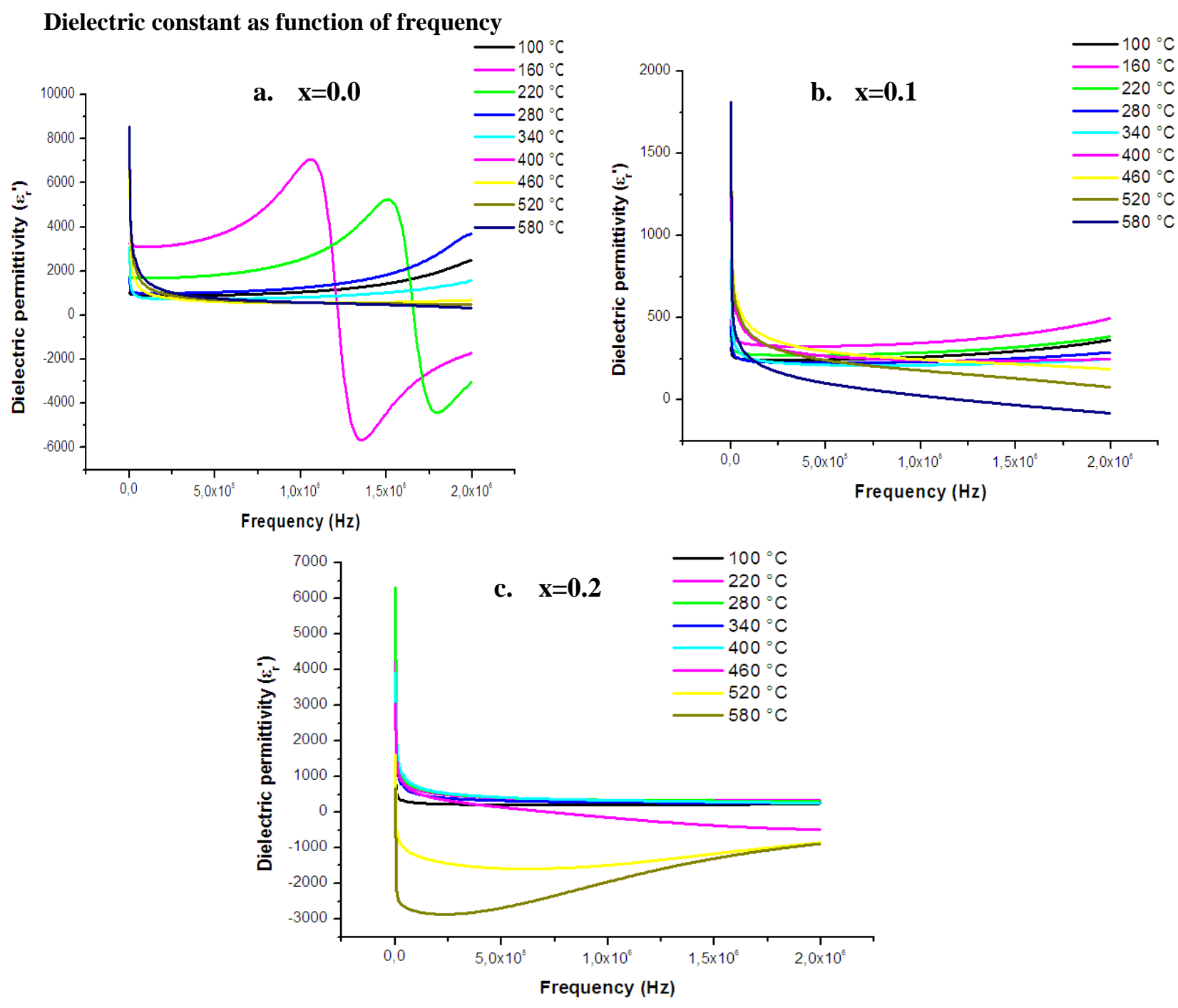
measuring the constant dielectric dependent on the frequency at different temperature as shown in Fig. 4 for $\mathrm{Ba}_{0.95} \mathrm{Bi}_{0.05} \mathrm{Ti}_{1-\mathrm{x}} \mathrm{Fe}_{\mathrm{x}} \mathrm{O}_{3}$ ceramics with $\mathrm{x}=\mathrm{a} .0 .0$, b. 0.1 and c. 0.2. For $\mathrm{Ba}_{0.95} \mathrm{Bi}_{0.05} \mathrm{TiO}_{3}$ compound (Fig $3 \mathrm{a})$, the dielectric constant presents a particular evolution with the increase of frequency. $\varepsilon_{\mathrm{r}, \max }$ reaches a maximum with the increase of frequency and then decreases and reaches a minimum. This

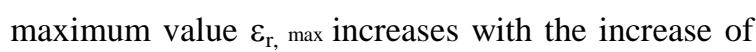
temperature to 8000 for $\mathrm{T}^{\circ}=160{ }^{\circ} \mathrm{C}$ and then decrease. For Fe-doped $\mathrm{Ba}_{0.95} \mathrm{Bi}_{0.05} \mathrm{TiO}_{3}$ at $\mathrm{x}=0.1$ and 0.2 (Fig. $3 b$ and $3 c$ ) we found that the relaxation phenomenon was eliminated or displaced to the high frequencies. Moreover, classical ferroelectric behavior is observed. So the $\mathrm{Fe}$ substitution eliminates the relaxation phenomenon and decreases the dielectric constant of the samples (Fig. $4 \mathrm{~b}$ and $4 c)$. Thus the drastic reductions in $\varepsilon_{\mathrm{r}}$ value upon $\mathrm{Fe}$ substitution can be attributed to the creation of oxygen vacancy due to $\mathrm{Fe}^{3+}$ ions replacing $\mathrm{Ti}^{4+}$ ions. Such oxygen vacancy leads to the breaking of Ti-O bonds and affects the dielectric constant ${ }^{20}$. 
Figure 4. Dielectric constant dependent frequency at different frequencies of $\mathrm{Ba}_{0.95} \mathrm{Bi}_{0.05} \mathrm{Ti}_{1-\mathrm{x}} \mathrm{Fe}_{\mathrm{x}} \mathrm{O}_{3}$ ceramics for $\mathrm{x}=$ a. 0.0 , b. 0.1 and c. 0.2 .

\section{Electric properties}

To understand the mechanism of the relaxation behavior in $\mathrm{Ba}_{0.95} \mathrm{Bi}_{0.05} \mathrm{Ti}_{1-\mathrm{x}} \mathrm{Fe}_{\mathrm{x}} \mathrm{O}_{3}$ ceramics the ColeCole plots from $100{ }^{\circ} \mathrm{C}$ to $400{ }^{\circ} \mathrm{C}$ of measurement temperature was studied. At the impedance spectrum study of $\mathrm{Ba}_{0.95} \mathrm{Bi}_{0.05} \mathrm{Ti}_{1-\mathrm{x}} \mathrm{Fe}_{\mathrm{x}} \mathrm{O}_{3}$ ceramic at $\mathrm{x}=0.1$ (Fig.5), all the curves showed a tendency to bend towards the abscissa to form semicircles with their centers below the real axis, having comparatively larger radii. For all ceramics (data not shown), the radii decrease with the increase of temperature, indicating negative temperature coefficient of resistivity (NTCR) behaviour of the materials ${ }^{21,22}$, generally found in case of semiconductors and at the same time showing a non-ideal Debye type behavior 23. This nonideal behavior could be attributed to several factors such as grain orientation, grain boundary, stress-strain phenomena, and atomic defect distribution ${ }^{24}$. The

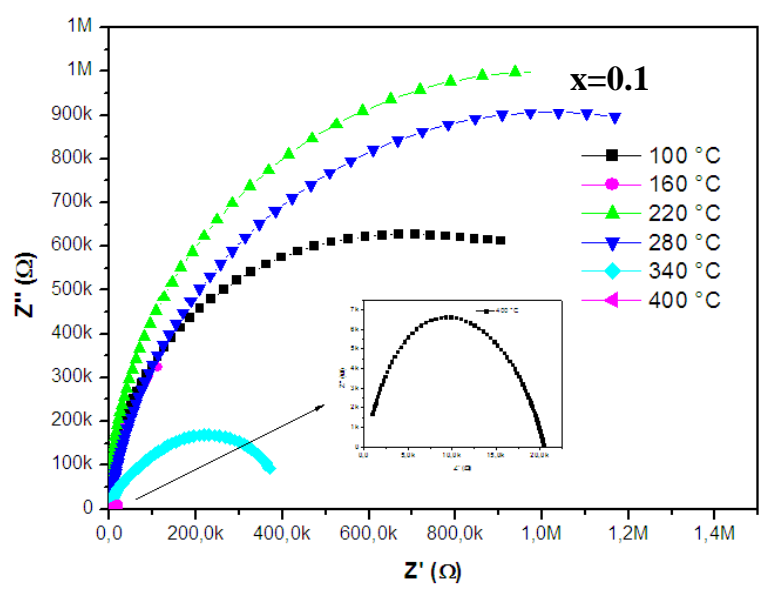

Figure 5. Complex impedance of $\mathrm{Ba}_{0.95} \mathrm{Bi}_{0.05} \mathrm{Ti}_{1}$ ${ }_{\mathrm{x}} \mathrm{Fe}_{\mathrm{x}} \mathrm{O}_{3}$ ceramics for $\mathrm{x}=\mathrm{a} .0 .0$, b. 0.1 and c. 0.2 at different temperature.

In order to co-relate the electrical parameters with the conduction process in the Fe-doped $\mathrm{Ba}_{0.95} \mathrm{Bi}_{0.05} \mathrm{TiO}_{3}$ ceramics, the ac conductivity is studied as a function of frequency. For Fig.7a two distinct regions are observed in the conductivity spectra of $\mathrm{Ba}_{0.95} \mathrm{Bi}_{0.05} \mathrm{TiO}_{3}$ sample. At lower frequencies, the conductivity is almost constant. This is the evidence for the frequency independent nature of the conductivity which represents the dc conductivity. While at high frequencies, the conductivity exhibits frequency dispersion due to the tremendous increase of the mobility of charge carriers in the materials ${ }^{26}$. In the high-frequency region, the conductivity increases with the frequency. At $x=0.1$ and 0.2 we observe two regions. The variation of conductivity in the low-frequency region is attributed to the polarization effects at the electrode and electrolyte interface. As the frequency reduces, more and more the charge accumulation impedance spectrum showed semicircles at and above the $520{ }^{\circ} \mathrm{C}, 400{ }^{\circ} \mathrm{C}, 400{ }^{\circ} \mathrm{C}$ temperatures for $\mathrm{x}=0.0$, $0.1,0.2$ respectively.

According to the impedance spectrum data obtained of $\mathrm{Ba}_{0.95} \mathrm{Bi}_{0.05} \mathrm{Ti}_{1-\mathrm{x}} \mathrm{Fe}_{\mathrm{x}} \mathrm{O}_{3}$ ceramics at $\mathrm{x}=0.0$, 0.1 and 0.2 at $400^{\circ} \mathrm{C}$ of measurement temperature, all the samples, are represented by a number of elements, one $\mathrm{R} / \mathrm{C}$ and other $\mathrm{R} / \mathrm{CPE}$ connected in series (Fig. 6). The plots and Tab.3 show that the grain resistivity increase with increases of $\mathrm{Fe}$ contents while the grain boundaries resistivity decreases as the concentration of $\mathrm{Fe}^{3+}$ increased from 0.0 to 0.2 . The Complex impedance spectrum of $\mathrm{x}=0.1$ and 0.2 samples show the presence of an arc of a circle with the center below the real axis indicating the contribution of the ceramic's boundaries, grain boundaries and electrode-interfaces ${ }^{25}$.

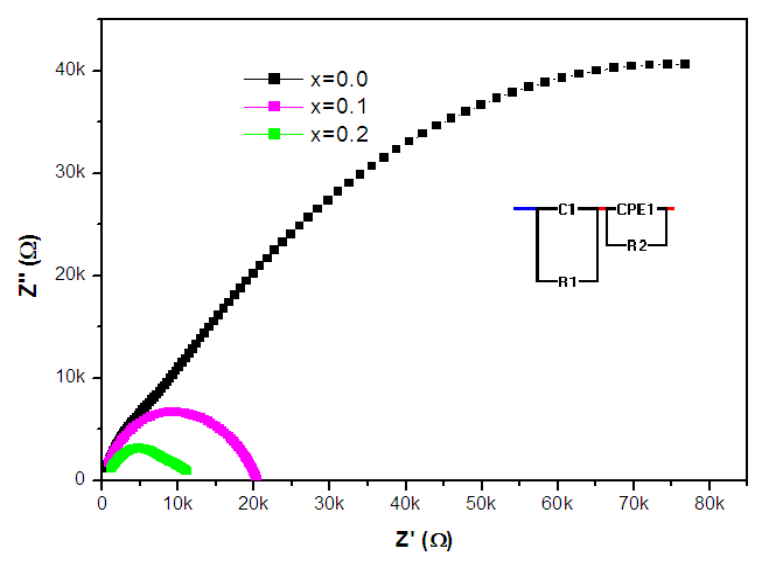

Figure 6. Complex impedance plots of

$\mathrm{Ba}_{0.95} \mathrm{Bi}_{0.05} \mathrm{Ti}_{1-\mathrm{x}} \mathrm{Fe}_{\mathrm{x}} \mathrm{O}_{3}$ ceramics for $\mathrm{x}=0.0,0.1$ and 0.2 measured at $400{ }^{\circ} \mathrm{C}$.

occurs at the electrode and electrolyte interface and hence, drop in conductivity. At high frequencies, the conductivity $\sigma_{\mathrm{ac}}$ (Fig. 7) plots to change their slops as a function of frequency with increasing Jonscher's exponent pointing due to the change of diffusive charge carrier transport to the hopping one ${ }^{27}$.

The frequency dependence of conductivity or socalled universal dynamic response (UDR) of ionic conductivity is related by a simple expression given by Jonscher's power law ${ }^{28}$ :

$\sigma_{\omega}=\sigma_{0}+\mathrm{A} \omega \mathrm{S}$

Where, $\sigma \omega$, is the ac conductivity, $\sigma 0$ is the limiting zero frequency conductivity $\sigma \mathrm{dc}, \mathrm{A}$ is a preexponential constant, $\omega=2 \pi \mathrm{f}$ is the angular frequency, and $\mathrm{s}$ is the power law exponent, where 0 $<\mathrm{s}<1$. 
Table 3. Grain and grain boundaries resistivity of different composition of $\mathrm{Ba}_{0.95} \mathrm{Bi}_{0.05} \mathrm{Ti}_{1-\mathrm{x}} \mathrm{Fe}_{\mathrm{x}} \mathrm{O}_{3}$ ceramics. Composition of $\mathrm{Ba}_{0.95} \mathrm{Bi}_{0.05} \mathrm{Ti}_{1-\mathrm{x}} \mathrm{Fe}_{\mathrm{x}} \mathrm{O}_{3} \quad$ Grain boundaries resistivity $\mathrm{R}_{\mathrm{GB}}(\Omega) \quad$ Grain resistivity $\mathrm{R}_{\mathrm{G}}(\Omega)$

a. $\quad x^{x=0.0}$
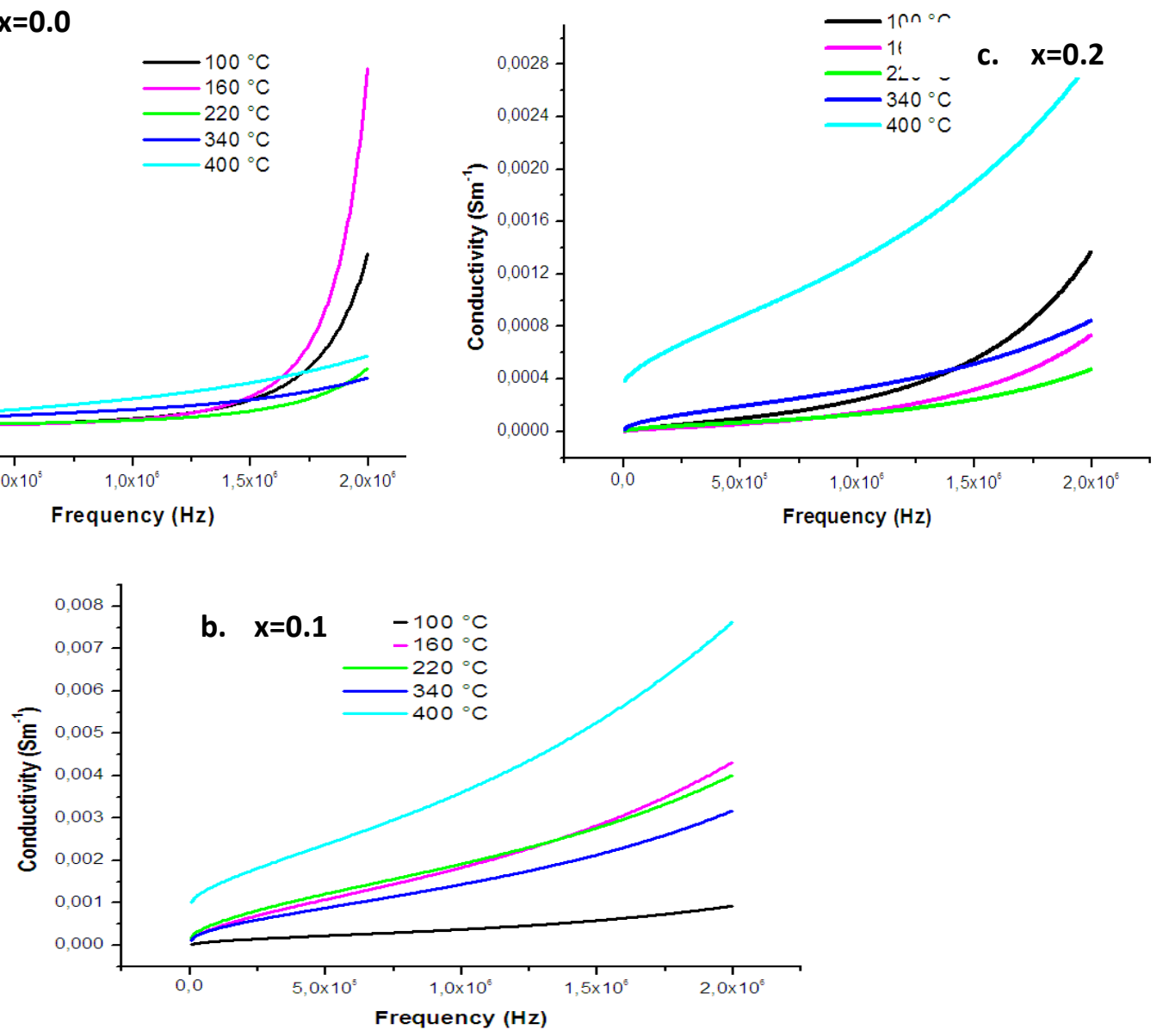

Figure 7. Ac conductivity plots of $\mathrm{Ba}_{0.95} \mathrm{Bi}_{0.05} \mathrm{Ti}_{1-\mathrm{x}} \mathrm{Fe}_{\mathrm{x}} \mathrm{O}_{3}$ ceramics for $\mathrm{x}=\mathrm{a} .0 .0$, b. 0.1 and c. 0.2 measured at different temperature

\section{Conclusion}

The effect of $\mathrm{Fe}$ substitution on structural and dielectric properties of $\mathrm{Ba}_{0.95} \mathrm{Bi}_{0.05} \mathrm{TiO}_{3}$ ceramics at $\mathrm{x}=0.0, \quad 0.1$ and 0.2 was studied. The X-ray diffractions showed the formation of only the tetragonal phase for $\mathrm{x}=0.0$ and 0.1 while the coexistence of tetragonal and hexagonal phase for $\mathrm{x}=0.2$ is observed. The dielectric measurement showed the existence of two maxima in the dielectric constant as a function of temperature corresponding to the two-phase transition. The first one is the phase transitions from a cubic paraelectric to a tetragonal ferroelectric at the Curie temperature $\left(\mathrm{T}_{\mathrm{C}} / \mathrm{T}_{\mathrm{m}}\right)$ while the second one is from a tetragonal to an orthorhombic ferroelectric at $\mathrm{T}_{\mathrm{T}-\mathrm{O}}$. This temperature shifted to lower temperature with

increase of $\mathrm{Fe}$ doping. The relaxation behavior present in all the samples is related to the defect dipoles such as the oxygen-vacancy and the valence fluctuation of $\mathrm{Fe}$ ions (between $\mathrm{Fe}^{3+}$ and $\mathrm{Fe}^{2+}$ ). The complex impedance spectroscopy approved the grain and grain boundary contributions towards electrical conductivity and the presence of a non-Debye type of relaxation in the majority of the materials. The frequency response of the conductivity for the test materials follows the Jonscher's power law. The Cole-Cole plots show that the electrical resistivity of 
the sample increases as the concentration of $\mathrm{Fe}^{3+}$ increased from 0.0 to 0.2 and the relaxation behavior in the test materials is found to be of non-Debye type.

\section{References}

1- K.F. Wang, J.-M. Liu and Z.F. Ren, Adv. Phys, 2000, 58,321.

2- Z.H. Chi, C.J. Xiao, S.M. Feng, F.Y. Li, C.Q. Jin, X.H. Wang, R.Z. Chen and L.T. Li, J. Appl. Phys, 2005, 98, Paper No. 103519.

3- M.M. Vijatovic, J.D. Bobic and B.D. Stojanovic, Sci. Sinter, 2008, 40, 155

4- Y.H. Chu, L.W. Martin, M.B. Holcomb, M. Gajek, S.J. Han, Q. He, N. Balker, C.H. Yang, D. Lee, W. Hu, Q. Zhan, P.L. Yang, A. Fraile Rodeiguez, A. Scholl, S.X. Wang and R. Ramesh, Nat. Mater, 2008, 7, 478.

5- S.Y. Qiu, W. Li, Y. Liu, G.H. Liu, Y.Q. Wu, N. Chen, Trans. Nonferrous Met. Soc. China, 2010, 20, 1911.

6- G.P. Du, Z.J. Hu, Q.F. Han, X.M. Qin, W.Z. Shi, J. Alloys Compd, 2010, 492, L79.

7- I. N. Apostolova, A. T. Apostolov, Safa Golrokh Bahoosh and Julia M. Wesselinowa. Journal of applied physics, 2013, 113, 203904.

8- X.P. Jiang, M. Zeng, K.W. Kowk, H.L.W. Chan, Key Eng. Mater, 2007, 334, 977.

9- Widi Yansen, Kadek Juliana Parwanta, Hadiyawarman, Deokhyeon Kim, Younmi Gwan, Jaeyeong Kim, Chunli Liu, Chang Uk Jung and Bo Wha Lee. Journal of the Korean Physical Society, , 2013, pp. 306-309

10- N. Vittayakorn, J. Appl. Sci. Res, 2006, 2 (12), 1319.

11- QIU Shen-yu, LI Wang, Liu Yu, Liu Guihua,Wu Yi-qiang and Chen Nan. Trans. Nonferrous Met. Soc. China, 2010, 20, 1911-1915.

12- P.Zhang, D.Grinting, S.Yu, N.Nghia, N.Dang and V.Lam. J.Appl.Phys, 2012, 112, 013909.
13- Poonam Kumari, Radheshyam Rai, Seema Sharma and M. A. Valente. journal of advanced dielectrics, 2017, 1750034 (10 pages).

14- Fayçal Bourguiba, Ah. Dhahri, Tarek Tahri, J. Dhahri, N. Abdelmoula, K. Taibi, E.K. Hlil. Journal of Alloys and Compounds, 2016, 675, $174 \mathrm{e} 182$.

15- N. Gouitaa, T. Lamcharfi, MF. Bouayad, F. Abdi, N.S. Echatoui and N. Hadi. Asian Journal of Chemistry, 2017, 2143-214.

16- X.K. Wei, Y.T. Su, Y. Sui, Z.X. Zhou, Y. Yao, C.Q. Jin and R.C. Yu, J.Appl. Phys, 2013, 102, 242910.

17- P.R. Mandal and T.K. Nath. J. Alloys Compd, 2015, 628, 379e389.

18- Yuwen Liu, Yongping Pu, Zixiong Sun and Qian Jin. Mater. Res. Bull, 2015, 70, $195 \mathrm{e} 199$.

19- C. Ang, Z. Yu, Z. Jing, P. Lunkenheimer and A. Loidl. Phys. Rev, 2000, B 61, 3922.

20- B. Deka, S. Ravi, A. Perumal and D. Pamu, Physica B, 2014, 448, 204.

21- P.Ouyang, H. Zhang, D.Xue and Z.Li. Materials in Electronics. October, 2013, pp 3932-3939.

22- D. Xue, H. Zhang, Y. Li, Y. Liu and Z. Li. Journal of Materials Science: Materials in Electronics. July, 2012, pp 1306-1312.

23- H. Khelifi, I.Zouari, A. Al-Hajry, N. Abdelmoula, D. Mezzane and H. Khemakhem. Ceramics International, 2015, 41, 12958- 12966.

24- N.Gouitaa, T.Lamcharfi, Mf.Bouayad, F.Abdi, N.Hadi. Journal of Materials Science: Materials in Electronics, 2018, p6797-6804. 8p.

25- H. D. Li, C. D. Feng, and P. H. Xiang. Jpn. J. Appl. Phys, 2003, pp.7387 7391.

26- Shujahadeen B. Aziz, Omed Gh. Abdullah, Salah R. Saeed and Hameed M. Ahmed. Int. J. Electrochem. Sci, 2018, 13, 812.

27- H. Khelifi, I.Zouari, A. Al-Hajry, N. Abdelmoula, D. Mezzane and H. Khemakhem. Ceramics International, 2015, 41, 12958-12966.

28- A. K. Jonscher. Journal of Materials Science August, 1981, pp 2037-2060. 